\title{
N-Linked Oligosaccharides Are Not Involved in the Function of a Cell-Cell Binding Glycoprotein E-Cadherin
}

\author{
Yasuaki Shirayoshi, Akinao Nose, Kaori Iwasaki, and Masatoshi Takeichi \\ Department of Biophysics, Faculty of Science, Kyoto University, Kitashirakawa, \\ Sakyo-ku, Kyoto 606, Japan
}

\begin{abstract}
E-cadherin is a $\mathrm{Ca}^{2+}$-dependent cell-cell adhesion molecule identified as a glycoprotein with a molecular weight (MW) of 124,000. To study the role of the sugar moieties of this adhesion molecule, we tested the effect of tunicamycin on aggregation mediated by E-cadherin of teratocarcinoma cells.

Immunoblot analysis using a monoclonal antibody to E-cadherin showed that in cells treated with tunicamycin this adhesion molecule is converted into two forms with MW of 118,000 and 131,000. The smaller one was exposed on the cell surface and showed a trypsin sensitivity characteristic to E-cadherin, suggesting that this is the peptide moiety of E-cadherin whose glycosylation with N-linked oligosaccharides was blocked by tunicamycin. The larger one was not removed by trypsin treatment of cells, suggesting an intracellular location.

These tunicamycin-treated cells aggregated in a $\mathrm{Ca}^{2+}$-dependent manner, and the aggregation was inhibited by a monoclonal antibody to E-cadherin. These results suggested that $\mathrm{N}$-linked oligosaccharides are not involved in the functional sites of this adhesion molecule.
\end{abstract}

E-cadherin is a class of $\mathrm{Ca}^{2+}$-dependent cell-cell adhesion molecules expressed by early embryonic cells, teratocarcinoma cells, and epithelial cells of many kinds of tissues $(12,22)$. This adhesion molecule is thought to be a key factor in the connection of these cells, since a monoclonal antibody ECCD-1 raised against E-cadherin tended to actively disrupt their mutual adhesion. E-cadherin is composed of a set of proteins with molecular weights (MW) of 124,000, 104,000, 85,000 $(12,22)$, of which that of 124,000 daltons $(124 \mathrm{kd})$ was the major component. In view of the MW and tissue distribution pattern, it is believed that E-cadherin is identical to uvomorulin $(13,22)$ and homologous to chicken L-CAM (5) and human cell-CAM 120/80 (4), which were identified in other laboratories.

E-cadherin or these homologous molecules appear to have sugar moieties. Peyrieras et al. $(13,14)$ showed that uvomorulin has at least one N-linked oligosaccharide chain, and Cunningham et al. (3) showed that L-CAM has four N-linked oligosaccharide chains. It is also known that these molecules can bind to concanavalin A $(4,5,8)$. The relationship of the sugar moieties of E-cadherin to its function, however, remains to be determined.

It has often been suggested that polysaccharides on cell surfaces may be concerned 
with cell adhesion and recognition (7). Compaction of mouse embryos was inhibited by tunicamycin $(16,17)$, and this process was also partially blocked by oligosaccharides (1). Grabel et al. (6) observed partial inhibition of aggregation of teratocarcinoma cells by lectin inhibitors. Knudsen (9) showed that aggregation of myoblasts was affected by tunicamycin. Shur (15) also suggested that galactosyltransferase has some role in cell adhesive behavior.

Sugar moieties of glycoprotein are classified into two groups, N-linked and O-linked oligosaccharides. It is known that tunicamycin blocks synthesis of $\mathrm{N}$-linked oligosaccharides (18); cells cultured with tunicamycin, therefore, express proteins without N-linked oligosaccharide chains.

Here we attempted to elucidate the relationship between the functional sites and the N-linked oligosaccharides of E-cadherin. We obtained a new monoclonal antibody to E-cadherin, ECCD-2, for immunochemical analysis of this adhesion molecule: the ECCD-1 thus far available is not useful for this kind of assay because of its low binding affinity to antigens. The effect of tunicamycin on synthesis of E-cadherin and on aggregation of teratocarcinoma F9 cells mediated by E-cadherin was then examined. The results suggested that the $\mathrm{N}$-linked oligosaccharides are not involved in the function of E-cadherin. This study also suggested that a precursor of E-cadherin cannot be processed into the functional form after tunicamycin treatment.

\section{MATERIALS AND METHODS}

Cell lines and antibodies. F9 and A211 (11) teratocarcinoma cells were maintained in Dulbecco's modified Eagle's essential medium (DMEM) supplemented with $10 \%$ fetal calf serum (DMEM-10F). A polyspecific antiserum to mouse liver (anti-liver) and a monoclonal antibody to E-cadherin, ECCD-1, were prepared as described $(12,22)$, both of which induce disruption of cell-cell adhesion when added to cell cultures, by blocking the action of E-cadherin.

Partial purification of tryptic fragments of E-cadherin. The livers of ICR mice were perfused serially with the following solutions: (1) $2.5 \mathrm{ml}$ of heparin $(1,000 \mathrm{units} / \mathrm{ml})$ in Hepes-buffered saline containing $137 \mathrm{mM} \mathrm{NaCl}, 4.7 \mathrm{mM} \mathrm{KCl}, 2 \mathrm{mM} \mathrm{CaCl}, 0.65 \mathrm{mM}$ $\mathrm{MgSO}_{4} \cdot 7 \mathrm{H}_{2} \mathrm{O}$ and $10 \mathrm{mM}$ Hepes- $\mathrm{NCl}$ (pH 7.4) (abbreviated to HBS), (2) 20 to $30 \mathrm{ml}$ of HBS, and (3) $20 \mathrm{ml}$ of $0.001 \%$ trypsin in $\mathrm{Ca}^{2+}$-free HBS supplemented with $1 \mathrm{mM}$ EGTA. The perfusion was performed by pumping these solutions into the portal vein of anesthetized mice at a constant rate of one $\mathrm{ml} / \mathrm{min}$ at room temperature and collecting them from the vena cava inferior. The perfusates of the first and second solutions were discarded and that of the third solution (defined as "TE perfusate") was saved. To this solution, collected from 200 individuals, were added $1 \mathrm{mM}$ phenylmethylsulfonylfluoride and $5 \mathrm{mM} \mathrm{CaCl}_{2}$ in final concentration. After filtering through a millipore filter $(0.45 \mu \mathrm{m}$ in pore size $)$, the TE perfusate was loaded onto a column of $10 \mathrm{ml}$ AFFI-GEL 15 (Bio Rad) conjugated with $220 \mathrm{mg}$ soybean trypsin inhibitor (Sigma, type 1-S) to remove trypsin. Unbound materials were concentrated by ultrafiltration through an Amicon YM10 membrane and then fractionated on a Sephacryl S200 column (Pharmacia). Fractions were tested for activity in neutralizing the anti-liver whose addition to culture of A211 cells induces disruption of their mutual adhesion, as described below. Fractions with this activity were loaded onto a DEAE cellulose (Whatman DE52) column equilibrated with $0.1 \mathrm{M}$ acetate buffer, $\mathrm{pH}$ 5.0. The column was eluted with a linear gradient of $200 \mathrm{ml}$ of $0.1 \mathrm{M}$ acetate buffer and $200 \mathrm{ml}$ 
of the same buffer containing $0.5 \mathrm{M} \mathrm{NaCl}$. Fractions with the neutralizing activity (the DEAE active fraction) were pooled and dialyzed against HBS.

Anti-liver neutralizing assay for detection of tryptic fragments of E-cadherin. A onehundred- $\mu l$ aliquot of each fraction of the chromatographed TE perfusate was dialyzed against HBS and mixed with $100 \mu \mathrm{l}$ of DMEM containing $10 \%$ heat-inactivated anti-liver and fetal calf serum. These mixtures were added into each well of Falcon 96-well plates (Becton Dickinson, 3072) containing colonies of A211 cells. After 3 to 5 hours, the effect of the anti-liver on cell-cell adhesion was examined using an inverted microscope.

Preparation of monoclonal antibodies to tryptic fragments of E-cadherin. A Donryu rat was injected intraperitoneally with $2 \times 10^{8} \mathrm{~F} 9$ cells in Hanks' balanced saline. This animal was given two boosters of the DEAE active fraction containing about $20 \mu \mathrm{g}$ protein mixed with Freund's incomplete adjuvant at intervals of three and four weeks. Three days after the third injection, splenocytes were fused with P3-X63-Ag-Ul myeloma cells as previously described (22). One to two weeks after fusion, culture supernatants of hybridoma were screened by the enzyme linked immunosorbent assay (ELISA) to detect antibodies reacting with the DEAE active fraction. Positive hybridoma supernatants were re-screened by immunoblot analysis against the DEAE fraction using the biotin-avidin system (Amersham). These were then examined to determine whether they reacted with the intact form of Ecadherin as defined by their characteristic molecular weight and trypsin sensitivity by immunoblot analysis. One hybridoma clone producing antibodies to E-cadherin (ECCD-2) was chosen for further study. ECCD-2 was an IgG type and did not bind to Protein A.

Cell culture with tunicamycin. F9 cells were cultured in DMEM-10F containing varying concentrations of tunicamycin (Sigma) for 8-10 h, harvested with trypsin in the presence of EDTA, and cultured again for $24 \mathrm{~h}$ in the presence of tunicamycin at the same concentration as used in the first treatment. Cells treated with tunicamycin were then harvested for further experiments.

Cell dissociation and aggregation assay. F9 cells were harvested by incubating with $0.01 \%$ trypsin in the presence of $2 \mathrm{mM} \mathrm{Ca}^{2+}$ (TC) or $1 \mathrm{mM} \mathrm{EGTA} \mathrm{(TE)} \mathrm{for} 20 \mathrm{~min}$ at $37^{\circ} \mathrm{C}$, as described (21). Suspensions of these cells were incubated on a gyratory shaker in the presence of $1 \mathrm{mM} \mathrm{Ca}^{2+}$ to test whether or not they could form aggregates mediated by E-cadherin as described (21). The effect of ECCD-1 on aggregation of these cells was tested as described earlier (22).

Electrophoresis and immunoblot analysis. Sodium dodecyl sulphate-polyacrylamide gel electrophoresis (SDS-PAGE) and preparation of samples for this analysis were performed as described (21). Immunoblot analysis was carried out according to the method of Towbin et al. (19), except that blots on nitrocellulose sheets were coated with $5 \%$ skim milk instead of using albumin, as suggested by Miskimins et al. (10). Antigens reacting with ECCD-2 were detected by the second antibody, ${ }^{125} \mathrm{I}$-anti-rat Ig (Amersham).

\section{RESULTS}

Isolation of a new monoclonal antibody to E-cadherin. The perfusate of liver with trypsin and EGTA (TE perfusate) contained materials which can absorb antibodies in the anti-liver inhibiting action of E-cadherin. We isolated a monoclonal antibody, termed ECCD-2, which recognizes two components with MWs of 36,000 and 34,000 present in the partially purified fraction of TE perfusate (DEAE active fraction) (Fig. 1a). When the ECCD-2 antibody was subjected to immunoblot analysis for detection of antigens from whole proteins of F9 cells, we found that it reacted with 
one major band with MW of 124,000 and occasionally with two minor bands with MWs of 104,000 and 85,000 (Fig. 1b). This reaction profile of ECCD-2 to F9 cell proteins was exactly the same as that of ECCD-1 (22), although the former was much more sensitive in detecting these bands. The bands were degraded by treatment of cells with trypsin in the absence of $\mathrm{Ca}^{2+}$ (Fig. 1d) but not in the presence of $\mathrm{Ca}^{2+}$ (Fig. 1c).

All these results indicate that ECCD-2 is an antibody recognizing E-cadherin and that the $36 \mathrm{kd}$ and $34 \mathrm{kd}$ components recognized by this antibody are tryptic fragments of the $124 \mathrm{kd}$ molecule. This is consistent with our previous observation that a tryptic fragment of E-cadherin in F9 cells had a MW in this range (21). ECCD-2 did not inhibit cell-cell adhesion when added to cell cultures, and binding of ECCD-2 to its antigen molecules was not $\mathrm{Ca}^{2+}$-dependent. These properties of ECCD-2 are different from those of ECCD-1, suggesting that these antibodies recognize distinct epitopes on the same molecule.

Effect of tunicamycin on E-cadherin synthesis. F9 cells were cultured in the presence of various concentrations of tunicamycin. Immunoblot analysis showed that the MW of E-cadherin bands is changed by incubation of cells in tunicamycin. In cells treated with 0.4 to $0.8 \mu \mathrm{g} / \mathrm{ml}$ of tunicamycin, ECCD-1 recognized two bands: one

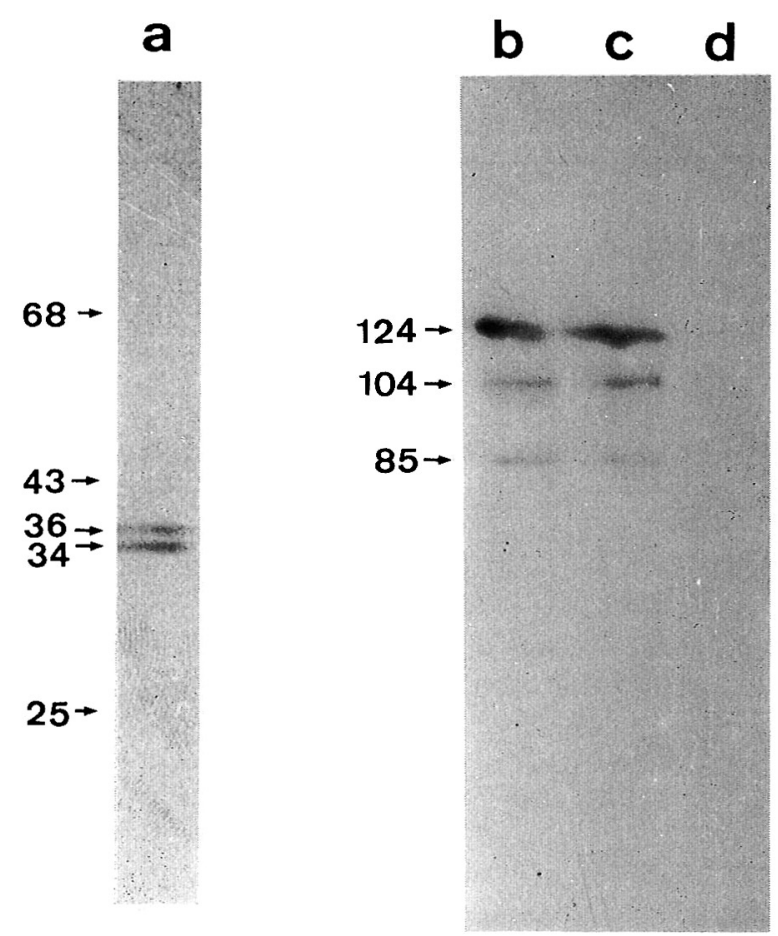

Fig. 1. Immunoblot analysis of antigens to the monoclonal antibody ECCD-2. a, antigens in the DEAE active fraction of TE perfusate. $b$ to $d$, antigens in F9 cells non-trypsinized (b), trypsinized in the presence of $\mathrm{Ca}^{2+}$ (c) and trypsinized in the presence of EGTA (d). Molecular weight markers used to determine the MWs of the antigens were: $\beta$-galactosidase (MW 116,000), phosphorylase-b (MW 94,000), bovine serum albumin (MW 68,000), ovalbumin (MW 43,000), and a-chymotrypsinogen A (MW 25,000). The positions of some of these markers are shown in (a). 


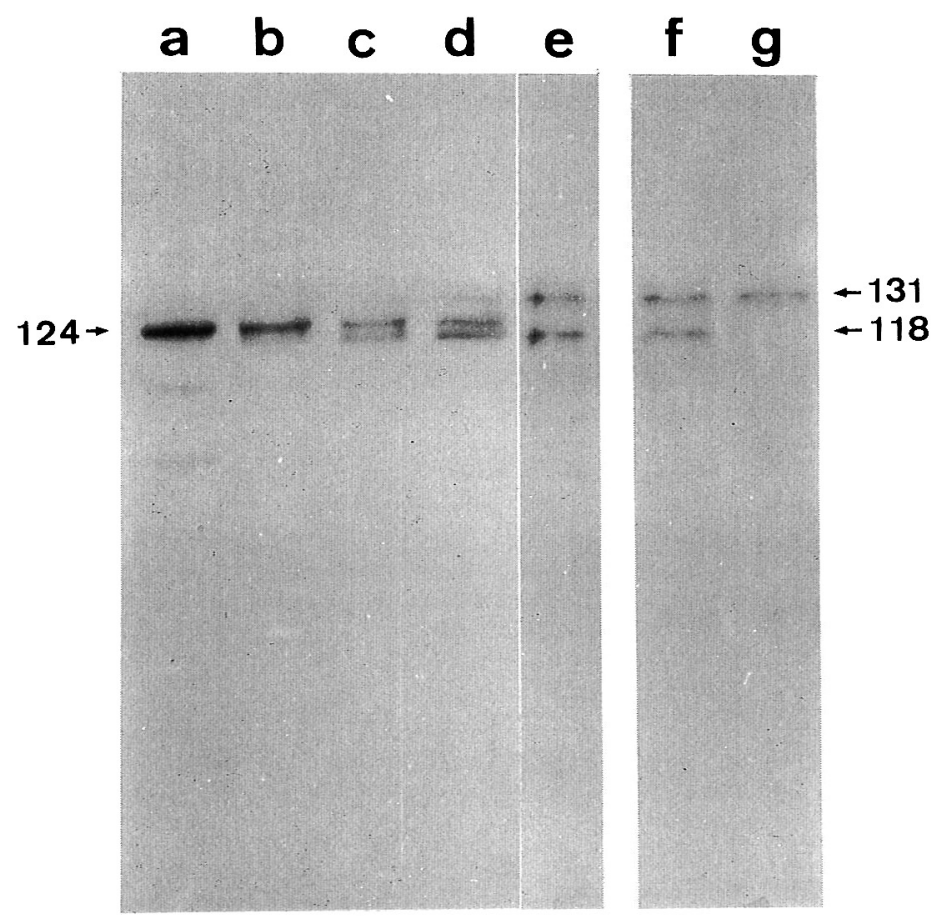

Fig. 2. Immunoblot analysis of E-cadherin in F9 cells cultured in the presence of tunicamycin. a, non-treated cells. $\mathrm{b}$ to e, cells incubated with $0.4 \mu \mathrm{g} / \mathrm{ml}$ (b), $0.8 \mu \mathrm{g} / \mathrm{ml}$ (c), $1.2 \mu \mathrm{g} / \mathrm{ml}$ (d), and $1.5 \mu \mathrm{g} / \mathrm{ml}$ (e) tunicamycin. $\mathrm{f}$ and $\mathrm{g}$, cells incubated in $1.5 \mu \mathrm{g} / \mathrm{ml}$ tunicamycin and treated with trypsin in the presence of $\mathrm{Ca}^{2+}$ (TC) (f) or in the presence of EGTA (TE) (g). These antigens were detected by the ECCD-2 antibody as in Fig. 1.

was the $124 \mathrm{kd}$ band, the original form of E-cadherin, and the other is a new band with MW of 118,000 which was not detected in non-treated cells (Fig. $2 a$ to c). In cells treated with $1.2 \mu \mathrm{g} / \mathrm{ml}$ of tunicamycin, a second new band with MW of 131,000 appeared (Fig. 2d). With tunicamycin at concentrations higher than $1.5 \mu \mathrm{g} / \mathrm{ml}$, the $124 \mathrm{kd}$ band disappeared and the $118 \mathrm{kd}$ and $131 \mathrm{kd}$ became the major bands reacting with ECCD-2 (Fig. 2e). From these results, we assume that $1.5 \mu \mathrm{g} / \mathrm{ml}$ of tunicamycin exerts its complete effect on glycosylation of E-cadherin.

To examine whether E-cadherin in the tunicamycin-treated F9 cells still has the characteristic trypsin sensitivity, these cells were harvested with trypsin in the presence of $\mathrm{Ca}^{2+}$ (TC) or in the absence of $\mathrm{Ca}^{2+}(\mathrm{TE})$, and analyzed for detection of E-cadherin bands by the immunoblot technique. Figure $2(\mathrm{f}, \mathrm{g})$ shows that the $118 \mathrm{kd}$ band is left intact on the TC-treated cells but disappears from the TE-treated cells. This property is exactly the same as that of the original $124 \mathrm{kd}$ band, suggesting that the $118 \mathrm{kd}$ component has the $\mathrm{Ca}^{2+}$-sensitive property characteristic of E-cadherin. The $131 \mathrm{kd}$ band, on the other hand, was not removed from cell surfaces, even by the TE-treatment (Fig. 2g). An immunocytochemical study showed that surfaces of the tunicamycin-treated cells are stained with ECCD-2 after TC-treatment, but not stained after TE-treatment in spite of the presence of the $131 \mathrm{kd}$ component in the cells (data not shown).

Function of E-cadherin without N-linked oligosaccharides. F9 cells were cultured 


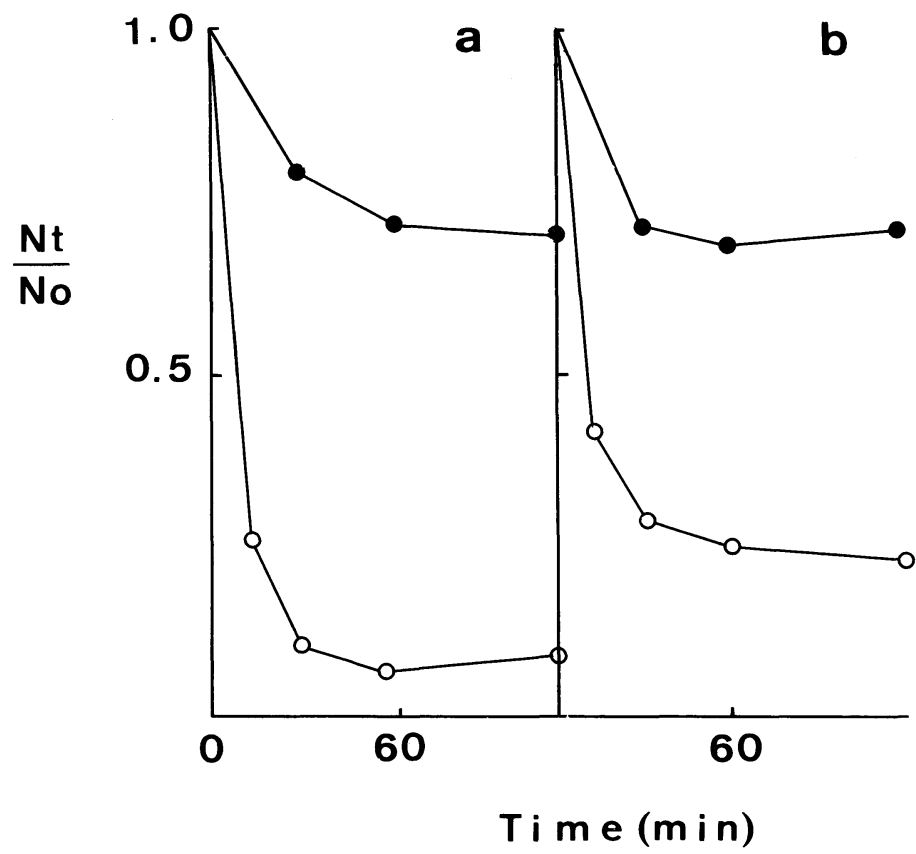

Fig. 3. Effect of tunicamycin on aggregation of F9 cells. Cells were cultured without (a) and with (b) $1.5 \mu \mathrm{g} / \mathrm{ml}$ tunicamycin and dissociated by the TC-treatment. They were allowed to aggregate in the presence $(\bullet)$ or absence $(O)$ of $25 \mu \mathrm{g} / \mathrm{ml}$ ECCD-1 antibody. The degree of cell aggregation, measured by a Coulter counter, was represented by the index $\mathrm{Nt} / \mathrm{No}$, where No is the total cell number and $\mathrm{Nt}$ is the total particle number at incubation time $\mathrm{t}$, as described earlier (20).

in the presence of $1.5 \mu \mathrm{g} / \mathrm{ml}$ tunicamycin. The cells tended to round up in these cultures, but the adhesion of those mediated by E-cadherin appeared to be maintained, since addition of ECCD-1 to the cultures induced stronger rounding up of cells (data not shown). Activity of E-cadherin on F9 cells treated with tunicamycin was then assayed by measuring their aggregation. The tunicamycin-treated cells harvested by TC treatment aggregated strongly in the presence of $\mathrm{Ca}^{2+}$, although their aggregation rate was slightly lower than that of nontreated cells (Fig. 3). This aggregation was inhibited by ECCD-1 to the same extent as that of non-treated F9 cells (Fig. 3).

\section{DISCUSSION}

The effect of tunicamycin on synthesis of E-cadherin observed in the present study suggested that E-cadherin has N-linked oligosaccharide chains, as also suggested by other workers $(3,13,20)$. Treatment of F9 cells with tunicamycin caused modification of E-cadherin into two forms; one form was smaller $(118 \mathrm{kd})$ than the original E-cadherin $(124 \mathrm{kd})$. Its small size suggests that this is probably a peptide whose glycosylation with $\mathrm{N}$-linked oligosaccharides was blocked by tunicamycin. This idea is consistent with the results obtained by Peyrieras et al. (14) that size of uvomorulin/E-cadherin in teratocarcinoma cells is slightly reduced 
after tunicamycin treatment and that this modified molecule is not labeled with galactose and glucosamine.

The other form was larger $(131 \mathrm{kd})$ than the original E-cadherin. This molecule could not be digested by treatment of cells with trypsin, although all other forms of E-cadherin were readily removed from the cell surface by trypsin in the absence of $\mathrm{Ca}^{2+}$. This strongly suggests that the $131 \mathrm{kd}$ component is not exposed on the cell surface. Immunofluorescence staining experiments supported this idea. Experiments of pulse-labeling of cells with radiolabelled amino acids also detected a larger form of uvomorulin $(13,14)$. These observations suggest that the $131 \mathrm{kd}$ component is a precursor of the functional form of E-cadherin. The precursor probably cannot be processed into the $124 \mathrm{kd}$ form and cannot be transported onto the cell surface by a still-unknown mechanism when glycosylation is blocked by tunicamycin. The $118 \mathrm{kd}$ form possibly escaped from this tunicamycin block, even though its own glycosylation was inhibited.

The results of aggregation experiments presented here show that tunicamycin has essentially no effect on the activity of E-cadherin. The slightly lower aggregation rate in tunicamycin-treated cells is possibly due to a smaller amount of the functional E-cadherin present on the surfaces of these cells than on those of non-treated cells, as assumed from the above discussion that this molecule may not be normally processed in the presence of tunicamycin. Knudsen (9) also showed that chicken myoblasts treated with tunicamycin can aggregate in a $\mathrm{Ca}^{2+}$-dependent manner if protease inhibitors are present. Peyrieras et al. (14) suggested that E-cadherin/ uvomorulin has no O-linked oligosaccharides and that these adhesion molecules on cells treated with tunicamycin have lost most of their sugar moieties. All these results suggest that the functional sites of E-cadherin are not located on its sugar moieties. Although many reports have suggested possible involvement of polysaccharides in cell-cell adhesion, such observations may not be relevant to the E-cadherin system. Analysis of the sugar moieties of N-CAM, a $\mathrm{Ca}^{2+}$-independent adhesion glycoprotein, also suggested that the sugars are not directly involved in their functional sites, although they seem to exert an indirect effect on the activity of the peptide moiety (2). Thus, the basic process of cell-cell adhesion appears to be governed by interactions of peptides rather than by interactions of oligosaccharides.

Acknowledgements. We thank Prof. T.S. Okada for his support on this project. The work was supported by the Toray Science Foundation and also by research grants from the Ministry of Education, Science and Culture of Japan.

\section{REFERENCES}

1. BIRD, J.M. and S.J. KimBer. Oligosaccharides containing fucose linked $\alpha(1-3)$ and $\alpha(1-4)$ to N-acetylglucosamine cause decompaction of mouse morulae. Dev. Biol. 104, 449-460, 1984

2. Cunningham, B.A., S. Hoffman, U. Rutishauser, J.J. Hemperly and G.M. Edelman. Molecular topography of the neural cell adhesion molecule N-CAM: Sugar orientation and location of sialic acid-rich and binding region. Proc. Natl. Acad. Sci. U.S.A. 80, 3116-3120, 1983

3. Cunningham, B.A., Y. Leutzinger, W.J. Gallin, B.C. Sorkin and G.M. Edelman. Linear organization of the liver cell adhesion molecule L-CAM. Proc. Natl. Acad. Sci. U.S.A. 81, 5787-5791, 1984

4. DAmSky, C.H., J. Richa, D. Solter, K. KnUdSen and C.A. BuCK. Identification and purification of a cell surface glycoprotein mediating intercellular adhesion in embryonic and adult tissue. Cell 34, 455-466, 1983 
5. Gallin, W.J., G.M. Edelman and B.A. Cunningham. Characterization of L-CAM, a major cell adhesion molecule from embryonic liver cells. Proc. Natl. Acad. Sci. U.S.A. 80, 1038-1042, 1983

6. Grabel, L.B., M.S. Singer, G.R. Martin and S.D. Rosen. Teratocarcinoma stem cell adhesion: The role of divalent cations and a cell surface lectin. J. Cell Biol. 96, 1532-1537, 1983

7. Harrison, F.L. and C.J. Chesterton. Factors mediating cell-cell recognition and adhesion/ Galaptins, a recently discovered class of bridging molecules. FEBS Lett. 122, 157-165, 1980

8. Hyafil, F., C. Babinet and F. JACOB. Cell-cell interactions in early embryogenesis: a molecular approach to the role of calcium. Cell 26, 447-454, 1981

9. KNudsen, K.A. The calcium-dependent myoblast adhesion that precedes cell fusion is mediated by glycoproteins. J. Cell Biol. 101, 891-897, 1985

10. Miskimins, W.K., M.P. Roberts, A. McClelland and F.H. Ruddle. Use of a proteinblotting procedure and a specific DNA probe to identify nuclear proteins that recognize the promoter region of the transferrin receptor gene. Proc. Natl. Acad. Sci. U.S.A 82, 6741-6744, 1985

11. Noguchi, T., C. Taya, T. Shiroishi, M. Noguchi, Y. Nishimune, Y. Ogiso, A. Matushiro and K. MoriwaKI. Normal diploid teratocarcinomas derived from B10 H-2 congenic mice. In Teratocarcinoma and Embryonic Cell Interactions, ed. Muramatsu, T., G. Gachelin, A.A. Moscona and Y. Ikawa. Japan Scientific Societies Press/Academic Press, Tokyo, pp. 41-56, 1982

12. Ogou, S., C. Yoshida-Noro and M. TAKeichi. Calcium-dependent cell-cell adhesion molecules common to hepatocytes and teratocarcinoma stem cells. J. Cell Biol. 97. 944-948, 1983

13. Peyrieras, N., F. Hyafil, D. Louvard, H.L. Ploegh and F. Jacob. Uvomorulin: A nonintegral membrane protein of early mouse embryo. Proc. Natl. Acad. Sci. U.S.A. 80, 6274-6277, 1983

14. Peyrieras, N., D. Louvard and F. Jacob. Characterization of antigens recognized by monoclonal and polyclonal antibodies directed against uvomorulin. Proc. Natl. Acad. Sci. U.S.A. 82, 8067-8071, 1985

15. SHuR, B.D. Embryonal carcinoma cell adhesion: the role of surface galactosyltransferase and its 90K lactosaminoglycan substrate. Dev. Biol. 99, 360-372, 1983

16. Surani, M.A.H. Glycoprotein synthesis and inhibition of glycosylation by tunicamycin in preimplantation mouse embryos: compaction and trophoblast adhesion. Cell 18, 217-227, 1979

17. Surani, M.A.H., S.J. Kimber and A.H. Handyside. Synthesis and role of cell surface glycoproteins in preimplantation mouse development. Exp. Cell Res. 133, 331-339, 1981

18. TAKasuki, A., A. Arima and G. TAmura. Tunicamycin, a new antibiotic. 1. Isolation and characterization of tunicamycin. J. Antibiot. (Tokyo) 24, 215-223, 1971

19. Towbin, H., T. Staehelin and J. Gordon. Electrophoretic transfer of proteins from polyacrylamide gels to nitrocellulose sheets: procedure and some applications. Proc. Natl. Acad. Sci. U.S.A. 76, 4350-4354, 1979

20. Vestweber, D. and R. KemLer. Identification of a putative cell adhesion domain of uvomorulin. EMBO J. 4, 3393-3398, 1985

21. Yoshida, C. and M. TAKeICHI. Teratocarcinoma cell adhesion: identification of a cell surface protein involved in calcium-dependent cell aggregation. Cell, 28, 217-224, 1982

22. Yoshida-Noro, C., N. Suzuki and M. TAKeichi. Molecular nature of the calcium-dependent cell-cell adhesion system in mouse teratocarcinoma and embryonic cells studied with a monoclonal antibody. Dev. Biol. 101, 19-27, 1984 